\section{The Role of Science in Civilization}

By Robert Bruce Lindsay. Pp. vii +318. (Now York and London: Harpor and Row, 1963.) 6.50 dollars; $49 s$.

$\mathrm{P}$

ROF. LINDSAY, who is dean of the Graduate School at Brown University, is woll known for his joint contributions (with Prof. Henry Margenau) to the philosophy of physical science, notably in the book Foundations of Physics, now widely available in the Dover paper-back series. The present work is a sequel to these earlier books.

Although the title leads one to expect a discussion centred on the sociological and historical aspects of science, what Dean Lindsay gives us turns out to be, for the most part, a fairly straightforward summary of the philosophical positions with which his name is already associated: that is to say, a variety of the 'logical empiricism' which was transplanted in the 'thirties to the United States from Vienna, where it was inspired by the teachings of the late Ernst Mach. To this summary, Prof. Lindsay adds, first, a concise discussion of 'information-theory', in its relations to language and thermodynamics; next, a brief survey of the problems arising out of the contemporary involvement of science with public affairs; and finally, an account of the author's own 'thermodynamic' theory of ethics, which revives the attempt originally made at the turn of the century by the distinguished chemist, Wilhelm Ostwald, to define an objective moral imperative in terms of (or on the analogy of) the physical ideas of 'order' and 'negative entropy'.

Having chosen to cover so much ground, Prof. Lindsay is compelled to proceed throughout at a gallop. We are taken from subject to subject at the double, and as a result scarcely one of the hundred-odd questions put up from under our feet is pursued for more than a few pages at a time. This compression will greatly reduce the book's value for serious students of the history, philosophy and sociology of science: too often, in place of cogent and careful arguments, we have to make do with summaries or with exclamation-marks (four in two paragraphs on pp. 68-69). To elomentary students, the work can be recommended chiefly for the compact account it provides of the fundamental doctrines of the logical empiricist school-particularly on the axiomatic structure of physical theories. Like others of the same school, Dean Lindsay is led by his preference for this kind of logical articulation to adopt a rather patronizing attitude towards "the scientific immaturity of biology", while his chapter on the politics of science takes us little way beyond the pre-war views of Michael Polanyi and John R. Baker about the essential autonomy of science.

STEPHEN TOULMIN

\section{Advances in Organometallic Chemistry}

Vol. 1. Edited by F. G. A. Stone and Robert West. Pp. $\mathrm{xi}+334$. (Now York: Academic Press, Inc.; London: Academic Press, Inc. (London), Ltd., 1964.) 888.

T $T$ is a pity that the publishers of this book have seen fit to bring out yet another new "Advances" series. There is less justification in this case than in some others, since the type of chemistry involved could well have been fitted into the publishors' own Advances in Inorganic and Radiochemistry -indeod, such organometallic articles have appoarod there in past issues. There are also numerous other existing roviow journals which could easily cope with the amount of material available.

This volume contains articles entitled "Diene-Iron Carbonyl Complexes and Related Species" (43 pages, Pettit and Emerson), "Reactions of Organotin Hydrides with Organic Compounds" (39 pages, Kuivila), "Organic Substituted Cyclosilanes" (48 pages, Gilman and Schwebke), "Fluorocarbon Derivatives of Metals" (74 pages, Treichel and Stone), "Conjugate Addition of Grignard Reagents to Aromatic Systems" (17 pages, Fuson), "Infra-red and Raman Spectral Studies of $\pi$ Complexes formed between Metals and $\mathrm{C}_{n} \mathrm{H}_{n}$ Rings" (72 pages, Fritz). The general level among these rather diverse topics appears to be quite high and the type of treatment is comparable to that in other review articles elsewhere; the last-mentioned article is perhaps the weakest in that it attempts to cover too much ground and is accordingly too discursive.

The book is well produced with adequate subject and author indexes. It will be of most use to research workers in the organometallic area, although, on account of the breadth of the field, ranging over widely different types of compounds, it may obviously not be of interest for porsonal libraries.

G. WILKINSON

\section{Organic Syntheses}

Collective Volume 4. Editor-in-Chief: Prof. Norman Rabjohn. A revised edition of Annual Volumes 30-39. Pp. xiv +1036 . (Now York and London: John Wiley and Sons, Inc., 1963.) 125s.

URING the past forty-two years, organic chemists have boen greatly indebted to the contributore and editors of the annual volumes of Organic Syntheses, in which the practical details of each synthesis were independently checked by at least two chemists; there must be exceedingly few organic research workers who have not used these volumes. The production of Collective Volumes every nine or ten years has been particularly valuable, because it has afforded an opportunity to incorporate any modifications in the experimental detail which later experience has shown desirable.

Collective Volume 4 is dodicated to Prof. Roger Adams, "one of the founders of Organic Syntheses, Inc., and its leader during the last forty-odd years". The book contains the usual wide spread of synthoses, which, even at this stage of development, still include the preparation of simple (but toxic) compounds such as cyanogen iodide and diazomethane. A spocial note is made of all compounds the preparations of which are described and which have since become commercially available. There is an increased number of warning notices of hazardous procedures or chemicals, based on information supplied by the users of the annual volumes, and indeed a pritited slip has been inserted to direct attention to one dangerous operation. Collective Volume 4, like its predecessors, is excellent and should be in every chemical library.

$$
\text { F. G. MANN }
$$

\section{Switching Theory in Space Technology}

Edited by Prof. Howard Aiken and William F. Main. Pp. $x+357$. (Stanford, Calif.: Stanford University Pross; London: Oxford University Press, 1963.) 92s. net.

A SYMPOSICM on "Application of Switching Theory A in Spaco Technology" was held in California during February 27-March 1, 1962, sponsored by the American Air Force Office of Scientific Research and the Lockheed Missiles and Space Co. Twenty-five papers were presented during the course of an introductory and four working sessions; these are reprinted in full here but without recording whether there was any concomitant discussion.

About half the papers are concerned with theoretical aspocts of circuit logics and switching systems, treating both analysis and synthesis of logical functions under the constraints introduced by the eventual need to turn the theory into practice. The topics include sequential digital networks, threshold logic, modular arithmetic and matrix algebra. The subject matter of papers dealing moro with the practice than the theory covers engineering techniques (for example, an abrasive technique for machining ferrites), system design (for example, digital data bandwidth compressor), and switching and stor- 